DOI: https://doi.org/10.34883/PI.2021.11.3.018

УДК 616.28-008.1-06-036.82/.85]:616.001.33(100)

Смычек В.Б. ${ }^{1}$, Макарина-Кибак Л.Э. ${ }^{2}$, Козлова С.В. ${ }^{1}$, Мириленко А.П. ${ }^{3}$

${ }^{1}$ Республиканский научно-практический центр медицинской экспертизы и реабилитации, Юхновка, Беларусь

2 Республиканский научно-практический центр оториноларингологии, Минск, Беларусь

${ }^{3}$ Белорусский государственный аграрный технический университет, Минск, Беларусь

Smychek V. ${ }^{1}$, Makaryna-Kibak L. ${ }^{2}$, Kozlowa S. ${ }^{1}$, Mirilenko A. ${ }^{3}$

${ }^{1}$ Republican Scientific and Practical Centre of Medical Assessment and Rehabilitation,

Yukhnovka, Belarus

${ }^{2}$ Republican Scientific and Practical Center of Otorhinolaryngology, Minsk, Belarus

${ }^{3}$ Belarusian State Agrarian Technical University, Minsk, Belarus

\title{
Методика экспертно-реабилитационной
} диагностики пациентов с последствиями заболеваний органа слуха с позиций Международной классификации функционирования, ограничений жизнедеятельности и здоровья

\author{
Method of Expert Rehabilitation Diagnostics of Patients \\ with Consequences of Auditory Organ Diseases from the Position \\ of the International Classification of Functioning, Disability \\ and Health
}

\section{Резюме}

Введение. Проведенный детальный анализ существующей системы медико-социальной экспертизы пациентов со слуховым дефицитом определил в ней ряд проблем как понятийно-концептуального, так и методического характера. Выявленные недостатки должны быть устранены путем создания новых теоретических основ и разработки современных методов, алгоритмов и критериев оценки последствий заболеваний органа слуха.

Цель. Разработать методику экспертно-реабилитационной диагностики пациентов с последствиями заболеваний органа слуха с позиций Международной классификации функционирования, ограничений жизнедеятельности и здоровья (МКФ) и провести по ней обследование пациентов со слуховыми нарушениями.

Материалы и методы. 129 пациентов трудоспособного возраста (от 17 до 56 (61) лет) с нарушениями слуха различной степени выраженности, проходивших освидетельствование в медико-реабилитационных экспертных комиссиях и ГУ «Республиканский научно-практический центр медицинской экспертизы и реабилитации» за период с 2016 по 2018 г. Разработка методики экспертно-реабилитационной диагностики этой категории лиц осуществлялась с позиций МКФ. 
Результаты. Разработана методика экспертно-реабилитационной диагностики пациентов с последствиями заболеваний органа слуха с позиций МКФ, которая включает совокупность новых методов оценки степени выраженности выявленных у лиц, включенных в научное исследование, нарушений структур и функций органа слуха и возникающих ограничений жизнедеятельности.

Выводы. Применение новой методики экспертно-реабилитационной диагностики пациентов с последствиями заболеваний органа слуха с позиций МКФ будет способствовать высокой степени объективности и индивидуализации выносимого экспертного решения.

Ключевые слова: пациенты с последствиями заболеваний органа слуха, экспертное аудиологическое исследование, экспертно-реабилитационная диагностика, Международная классификация функционирования, ограничений жизнедеятельности, структуры организма, функции организма, активность и участие, факторы окружающей среды.

\section{Abstract}

Introduction. A detailed analysis of the existing system of medical and social examination of patients with auditory deficits identified a number of problems of both conceptual and methodological nature in it. The identified shortcomings should be eliminated by creating new theoretical foundations and developing modern methods, algorithms and criteria for assessing the consequences of diseases of the hearing organ.

Purpose. To develop a methodology for expert-rehabilitation diagnostics of patients with consequences of diseases of the organ of hearing from the standpoint of the International Classification of the Functioning, Disabilities and Health (ICF) and to conduct examination of patients with hearing impairments using it.

Materials and methods. 129 patients of working age (from 17 to 56 (61) years) with hearing impairments of various severity, who were examined by medical and rehabilitation expert commissions and at the State Institution "Republican Scientific and Practical Centre of Medical Assessment and Rehabilitation" in the period from 2016 to 2018. Development of the methodology for expert-rehabilitation diagnostics of this category of persons was carried out from the standpoint of the ICF.

Results. The technique for expert-rehabilitation diagnostics of patients with the consequences of diseases of the organ of hearing from the standpoint of the ICF has been developed. It includes a set of new methods for assessing the severity of the disorders of the structures and functions of the hearing organ and disabilities that arise from them.

Conclusions. The use of the new methodology for expert-rehabilitation diagnostics of patients with consequences of diseases of the organ of hearing from the standpoint of the ICF will contribute to higher degree of objectivity and individualization of the expert decision.

Keywords: patients with consequences of auditory organ diseases, expert audiological examination, expert and rehabilitation diagnostics, International Classification of Functioning, Disability and Health, body structures, activities and participation, environmental factors.

\section{- ВВЕДЕНИЕ}

В последние годы в обществе изменились подходы к пониманию инвалидности от индивидуальной медицинской проблемы к социальнокультурному явлению. На сегодняшний день невозможно представить деятельность индивида без взаимодействия с факторами окружающей среды, которые облегчают или лимитируют его функционирование. 
Нарушения слуха относятся к социально значимому дефекту, так как приводят к медико-социальной дезадаптации в обществе и окружающей среде вследствие возникновения ограничений жизнедеятельности в таких категориях, как способность к общению, ориентации, обучению и трудовой деятельности.

Проведенный нами детальный анализ существующей системы медико-социальной экспертизы пациентов со слуховым дефицитом определил в ней ряд проблем как понятийно-концептуального, так и методического характера [1]. Выявленные недостатки должны быть устранены путем создания новых теоретических основ и разработки современных методов, алгоритмов и критериев оценки последствий заболеваний органа слуха.

\section{- ЦЕЛЬ ИССЛЕДОВАНИЯ}

Разработать методику экспертно-реабилитационной диагностики пациентов с последствиями заболеваний органа слуха с позиций Международной классификации функционирования, ограничений жизнедеятельности и здоровья (МКФ) и провести по ней обследование пациентов со слуховыми нарушениями.

\section{- МАТЕРИАЛЫ И МЕТОДЫ}

Для достижения цели настоящего исследования была сформирована репрезентативная выборка, объем которой составил 129 пациентов трудоспособного возраста (от 17 до 56 (61) лет) с нарушениями слуха различной степени выраженности, проходивших освидетельствование в медико-реабилитационных экспертных комиссиях и ГУ «Республиканский научно-практический центр медицинской экспертизы и реабилитации» за период с 2016 по 2018 г. Из них 69 (53,49\%) женщин и 60 (46,51\%) мужчин. Все лица, включенные в исследование, или использовали различные слуховые протезы, или нуждались в их применении. Этой категории граждан на базе ГУ «Республиканский научно-практический центр оториноларингологии» было проведено аудиологическое исследование с целью уточнения степени выраженности имеющихся у них слуховых нарушений и выполнена оценка эффективности слухопротезирования.

В процессе научной работы использованы следующие методы: аналитический, клинический, клинико-инструментальный, клиникоэкспертный. Разработка методики экспертно-реабилитационной диагностики пациентов со слуховыми нарушениями осуществлялась с позиций МКФ [2]. При этом оценке подлежали все составные части классификации как современной биопсихосоциальной модели: функции, структуры, активность и участие, факторы окружающей среды в виде облегчения или барьеров.

Статистическая обработка результатов исследования проводилась с применением стандартного пакета статистического и математического анализа программного приложения Microsoft Excel и StatSoft Statistica.

\section{- РЕЗУЛЬТАТЫ И ОБСУЖДЕНИЕ}

Методика экспертно-реабилитационной диагностики пациентов с последствиями заболеваний органа слуха с позиций МКФ включает 
совокупность разработанных методов оценки степени выраженности выявленных нарушений структур и функций органа слуха и возникающих ограничений жизнедеятельности.

\section{Методы экспертного аудиологического исследования пациен- тов со слуховыми нарушениями}

С целью разработки перечня обязательных и дополнительных аудиологических исследований, необходимых для установления развернутого экспертного клинико-функционального диагноза, нами проведено обследование 129 пациентов трудоспособного возраста с нарушениями слуха различной степени выраженности. При этом использовались не только стандартные аудиологические методы, но и специальные тесты как для оценки слухового дефицита и эффективности его коррекции техническими средствами, так и для исследования пространственного слуха.

На основании анализа данных, полученных в результате проведенного обследования лиц, включенных в научную работу, сформирован перечень обязательных и дополнительных методов аудиологического исследования пациентов с последствиями заболеваний органа слуха при направлении их на медико-социальную экспертизу.

К обязательным методам относятся:

- акуметрия;

- камертональные тесты (Ринне, Вебера, Федеричи);

- тональная пороговая аудиометрия в конвенциальном диапазоне частот $(0,125-8$ кГц);

- импедансометрия (тимпанометрия с дополнительными нагрузочными тестами и акустическая рефлексометрия);

- «Русский речевой аудиометрический речевой экспресс-тест» с дихотическим предъявлением многосложных слов как в тишине, так и на фоне многоголосия при отношении SNR $=+6$ дБ, с подачей записанных слов через головные телефоны на оба уха с введением интерауральной разницы по интенсивности [3];

- упрощенный вариант традиционной речевой аудиометрии с моноуральным предъявлением односложных слов через головные телефоны на лучше слышащее ухо при комфортном уровне громкости в тишине [3];

- методы оценки эффективности коррекции слуховых нарушений со слуховым протезом: акуметрия; тональная пороговая аудиометрия в конвенциальном диапазоне частот $(0,125-8$ кГц) в свободном звуковом поле; упрощенная традиционная речевая аудиометрия в свободном звуковом поле в тишине при предъявлении входного сигнала (многосложные слова) интенсивностью 65 дБ УзД [3]; «Русский речевой аудиометрический экспресс-тест» с предъявлением многосложных слов в свободном звуковом поле на фоне шума многоголосия при отношении SNR $=+6$ дБ [3].

В дополнительное экспертное аудиологическое исследование необходимо включить:

- объективные (физиологические) методы оценки слуха: регистрация вызванной отоакустической эмиссии (задержанной (ЗВОАЭ); регистрация коротколатентных слуховых вызванных потенциалов мозга (КСВП) и стационарных слуховых потенциалов мозга (ASSR); 
- методы сенсибилизированной (усложненной) речевой аудиометрии: «Русский речевой аудиометрический экспресс-тест» с предъявлением многосложных слов при отношении SNR = +6 дБ (многоголосие) на лучше слышащее ухо; тест чередующейся бинаурально речи (ЧБР) [3];

- методы оценки эффективности коррекции слуховых нарушений со слуховым протезом - «Русский речевой аудиометрический экспресс-тест» с предъявлением многосложных слов в свободном звуковом поле на фоне шума (шум ветра, дождя, транспорта) при отношении SNR = +6 дБ [3];

- метод определения установочного поведения у пациентов со слуховыми нарушениями $[4,5]$.

\section{Метод экспертной оценки нарушений структур органа слуха}

Разработанный метод экспертной оценки нарушений структур органа слуха с позиций МКФ включает детальное описание выявленных патологических изменений в слуховом анализаторе и определение степени их выраженности на основании проведенных исследований [6].

Из краткого базового набора МКФ-кодов для слуховых нарушений выбраны категории домена s2 - глаз, ухо и относящиеся к ним структуры, которые соответствуют морфологическим характеристикам, описывающим структуру периферического отдела слухового анализатора. К ним относятся: s2500 - барабанная перепонка, s2501 - евстахиева трубa, s2502 - косточки, s2508 - структура среднего уха, другая уточненная: холестеатома, s260 - структура внутреннего уха. Далее разработан перечень их параметров, по которым осуществляется оценка структур периферического отдела слухового анализатора.

Структуры органа слуха с позиций МКФ кодируются тремя определителями, первый из которых отражает величину нарушений, второй характер изменений, третий - локализацию нарушений. Разработаны критерии качественной и количественной оценки первого определителя, на основании которых устанавливается степень выраженности выявленных структурных нарушений в периферическом отделе слухового анализатора.

Проведено обследование всего контингента, включенного в научное исследование, с применением метода экспертной оценки нарушений структур органа слуха с позиций МКФ.

У 121 (93,8\% (95\% доверительный интервал (ДИ) от 88,2 до 97,3\%)) из 129 человек дефектов барабанной перепонки не обнаружено. У 5 (3,9\% (95\% ДИ от 1,3 до 8,8\%)) пациентов установлены стойкие незначительные нарушения ее структуры в виде рубцово-измененной тимпанальной мембраны или наличия в ней перфорации размерами до $<25 \%$ от общей площади. При микроотоскопии у 2 (1,6\% (95\% ДИ от 0,2 до 5,5\%)) человек визуализирована трепанационная полость с обеих сторон после перенесенной санирующей операции открытого типа (абсолютные нарушения). У одной (0,8\% (95\% ДИ от 0,0 до 4,2\%)) пациентки тимпанальная мембрана с обеих сторон была недоступна осмотру вследствие атрезии наружных слуховых проходов, в результате чего степень выраженности нарушений ее структуры закодировали числовым значением «8»- не определено. 
При оценке структуры евстахиевой трубы путем исследования ее вентиляционной функции у 119 (92,2\% (95\% ДИ от 86,1 до 96,5\%)) человек нарушений не выявлено. Первая степень проходимости слуховой трубы установлена у 6 пациентов (4,7\% (95\% ДИ от 1,7 до 9,9\%)), вторая у 2 (1,6\% (95\% ДИ от 0,2 до 5,5\%)), третья - у 1 (0,8\% (95\% ДИ от 0,0 до $4,2 \%))$. У одного (0,8\% (95\% ДИ от 0,0 до 4,2\%)) пациента исследовать ее вентиляционную функцию не представлялось возможным вследствие атрезии слуховых проходов с обеих сторон, в результате чего степень выраженности дефектов в структуре евстахиевой трубы закодировали числовым значением «8» - не определено. Необходимо отметить, что выявленные нарушения имели стойкий характер, так как при проведении баронагрузочных проб Тойнби, Вальсальвы, а также пустого глотка результаты повторной тимпанометрии не менялись.

По данным проведенной отомикроскопии и аудиологических исследований у 115 (89,1\% (95\% ДИ от 82,5 до 93,9\%)) пациентов из всего обследуемого контингента повреждения целостности цепи слуховых косточек не отмечалось. У одного (0,8\% (95\% ДИ от 0,0 до 4,2\%)) человека в ходе ревизии барабанной полости обнаружено разрушение лентикулярного отростка наковальни и арки стремени. В результате выполненной 4 (3,1\% (95\% ДИ от 0,9 до 7,8\%)) пациентам санирующей операции открытого типа на среднем ухе вследствие протекающего в нем хронического воспалительного процесса выявлено тотальное разрушение цепи слуховых косточек без осложнений. Девяти $(7,0 \%$ (95\% ДИ от 3,2 до 12,8\%)) пациентам с отосклерозом определить целостность слуховых косточек не представлялось возможным, так как отсутствовал метод их визуализации - компьютерная томография височных костей.

У всего контингента, включенного в исследование, холестеатома в наружном слуховом проходе и в полости среднего уха не обнаружена.

\section{Метод экспертной оценки нарушений функций органа слуха}

Для характеристики «речевого слуха» как социальной категории при проведении экспертной аудиологической диагностики разработан с позиций МКФ метод экспертной оценки таких его функций, как слышимость, разборчивость речи и ототопика. Он включает перечень параметров, описывающих функции слуха, а также критерии определения степени выраженности их нарушений [6].

Из краткого базового набора МКФ-кодов для слуховых нарушений выбраны следующие категории домена b2 - сенсорные функции и боль: b2300 - восприятие звука, b2302 - локализация источника звука, b2304 распознавание речи. Далее разработан перечень их параметров, по которым осуществляется оценка функций слуха. При этом величина возникающих в них проблем кодируется одним определителем. По результатам аудиологических субъективных (психоакустических) методов исследования разработаны критерии качественной и количественной оценки определителей каждой категории, отражающие величину выявленных нарушений функций слуха.

Всем 129 пациентам проведено обследование в соответствии с разработанным методом экспертной оценки нарушений функций органа слуха. 
У 2 (1,6\% (95\% ДИ от 0,2 до 5,5\%)) человек из числа всего контингента, включенного в исследование, выявлены незначительные нарушения в восприятии звука, у 5 (3,9\% (95\% ДИ от 1,3 до 8,8\%)) - умеренные, у 67 (51,9\% (95\% ДИ от 43,1 до 60,8\%)) - тяжелые, у 55 (42,6\% (95\% ДИ от 34,01 до $51,6 \%))$ - абсолютные.

При оценке способности локализации источника звука в пространстве 33 (25,6\% (95\% ДИ от 18,3 до 34,03\%)) пациента из 129 не испытывали затруднений в определении его направления. 30 (23,3\% (95\% ДИ от 16,3 до 31,5\%)) лицам в сложной акустической ситуации потребовалось увеличение длительности подачи сигнала и больше времени на определение стороны, в которую сместился слуховой образ. У 1 (0,8\% (95\% ДИ от 0,0 до 4,2\%)) человека выявлены трудности при обнаружении в тихой обстановке незнакомых звуков при полной сохранности локализации знакомых по звучанию. При этом у него отсутствовала такая способность на фоне шума. 46 (35,7\% (95\% ДИ от 27,4 до 44,6\%)) человек не определили сторону смещения слухового образа в сложной акустической ситуации, а также в тишине при предъявлении незнакомых сигналов. Для локализации знакомого по звучанию источника звука при отсутствии помех им потребовалась длительная и неоднократная его подача. 19 (14,7\% (95\% ДИ от 9,1 до 22,0\%)) пациентов не смогли установить направление прихода звуковой волны в горизонтальной плоскости. У 2 (1,6\% (95\% ДИ от 0,2 до 5,5\%)) человек пороги латерализации по интенсивности превысили 2 дБ, что является характерным диагностическим критерием центральных слуховых расстройств, наличие которых подтвердилось другими аудиологическими методами исследования.

На основании анализа данных, полученных в результате проведенного исследования, установлено, что показатель асимметрии слуха по порогам имеет исключительно сильную корреляционную связь с показателями способностей латерализовать источник звука в наушниках в горизонтальной плоскости как в тишине, так и на фоне шуме при SNR +6 дБ УЗД, а также определять его локализацию в пространстве. Коэффициенты корреляции $\left(r_{s}\right)$ составили соответственно 0,93, 0,93 и 0,98. Для всех случаев уровень статистической значимости имел значение $p<0,001$. Таким образом, можно сделать вывод о том, что чем больше асимметрия слуха по порогам, тем чаще возникают проблемы в способности обнаружить местонахождение звукового сигнала в различных акустических ситуациях. При асимметрии слуха более 40 дБ возникают трудности в локализации источника звука в тишине и становится невозможным определить направление прихода звуковой волны на фоне помехи в горизонтальной плоскости.

При количественной оценке «речевого слуха» как социальной категории путем применения упрощенной версии метода речевой аудиометрии с предъявлением односложных слов через головные телефоны в тишине при комфортном уровне громкости на лучше слышащее ухо установлено, что разборчивость речи у 1 (0,8\% (95\% ДИ от 0,0 до 4,2\%)) пациента достигла 95\%, у 13 (10,1\% (95\% ДИ от 5,5 до 16,6\%)) - от 70 до $90 \%$, у 20 (15,5\% (95\% ДИ от 9,7 до $22,9 \%))$ - от 45 до $65 \%$, у $24(18,6 \%$ (95\% ДИ от 12,3 до 26,4\%)) - 40\% и менее. 71 (55,0\% (95\% ДИ от 46,0 до $63,8 \%))$ человек не смог разобрать речевые сигналы даже на максимальном увеличении подаваемого звука. При этом обнаружена сильная 
корреляционная связь между степенью потери слуха на лучше слышащее ухо и процентом правильно воспроизведенных слов $\left(r_{s}=0,79\right.$, $p<0,001)$.

\section{Методы оценки когнитивных функций и эмоционально-воле-} вой сферы у пациентов со слуховым дефицитом

Проведение нейропсихологического исследования в экспертнореабилитационной диагностике пациентов с последствиями заболеваний органа слуха, с нашей точки зрения, является обязательным этапом, так как выявленные у них нарушения памяти и внимания, а также эмоционально-волевой сферы могут приводить к ограничениям жизнедеятельности по отдельным категориям или усугублять существующие проблемы в функционировании в условиях слухового дефицита.

С целью описания психологического статуса индивида с нарушениями слуха нами предложено оценивать такие высшие психические функции, как память и внимание, соответствующие следующим категориям домена b1 - умственные функции из краткого базового набора МКФ-кодов для потери слуха: b140 - функции внимания, b144 - функции памяти.

Для характеристики вышеуказанных когнитивных функций при проведении экспертно-реабилитационной диагностики пациентов с последствиями заболеваний органа слуха с позиций МКФ мы руководствовались инструкцией по применению «Метод медицинской реабилитации пациентов с расстройствами шизофренического спектра с использованием оценки реабилитационного потенциала и реабилитационного прогноза» [7]. В ней описаны критерии определения степени выраженности признаков снижения памяти и дефицита внимания, основанные на результатах тестирования с использованием методики запоминания 10 слов и таблиц Шульте [8].

Однако в предложенном методе для оценки памяти отсутствуют критерии, которые позволяют установить величину выявленных нарушений кратковременной памяти. Ее объем имеет первостепенное значение в распознавании устной речи, так как поступающая вербально слуховая информация должна восприниматься почти мгновенно, и слушающему необходимо сохранять в своем сознании все речевое высказывание, включая его интонационно-ритмическую структуру [9]. Для выявления расстройств кратковременной памяти (b1440) с позиций МКФ нами рекомендовано использовать интерпретацию результатов тестирования с применением методики запоминания 10 слов, предложенную сотрудниками кафедры социальной психиатрии и психологии Санкт-Петербургского института усовершенствования врачей-экспертов [10].

Для описания состояния эмоционально-волевой сферы лиц со слуховыми нарушениями из краткого базового набора МКФ-кодов для потери слуха выбрана категория b1521 - регуляция эмоций, которая включает умственные функции, контролирующие переживание и проявление аффекта. С целью ее оценки нами предложено применить такой параметр, как уровень тревожности, который оценивали по методике, разработанной Спилбергером Ч.Д., которая была адаптирована на русском языке Ханиным Ю.Л. [8]. Предложенную авторами 
интерпретацию результатов, полученных при проведении теста, ранжировали по 5-балльной негативной шкале, принятой за 100 процентов [6].

Проведено нейропсихологическое тестирование всех пациентов, включенных в научное исследование, с применением вышеуказанных методов и последующей оценкой степени выраженности выявленных нарушений отдельных когнитивных функций и эмоционально-волевой сферы с позиций МКФ. При этом выявлен тот факт, что для лиц с нарушениями слуха не характерна повышенная истощаемость внимания вследствие отсутствия избыточного «потребления» речевой информации, перегрузка которой может присутствовать у лиц с нормальным слухом.

\section{Метод оценки ограничений активности и возможности участия при последствиях заболеваний органа слуха}

Разработанный метод оценки ограничений активности и возможности участия при последствиях заболевания органа слуха с позиций МКФ включает следующие категории: d330 - речь, d3351 - составление и изложение сообщения посредством знаков и символов, d350 - разговор, d3600 - использование телекоммуникационных устройств, d3602 использование техник общения, d750 - неформальные социальные отношения, d220 - выполнение многоплановых задач, d825 - профессиональное обучение, d830 - высшее образование, 850 - оплачиваемая работа, перечень параметров, описывающих функционирование индивида в условиях слуховой среды, а также критерии определения степени выраженности проблем, которые он испытывает вследствие нарушения слухового восприятия при выполнении им задач или действий [6].

Оценка ограничений активности и возможности у 129 пациентов со слуховыми нарушениями проведена по разработанному методу.

В ходе анализа полученных данных установлено, что большинство лиц, включенных в научное исследование, испытывают различной степени трудности при функционировании в условиях слухового дефицита в рамках выбранных доменов активности и участия. При этом использование акустических средств для коррекции имеющихся у них слуховых нарушений уменьшает степень выраженности проблем, возникающих при вовлечении в жизненные ситуации (получены статистически значимые различия $\mathrm{p}<0,001$ [по критерию Уилкоксона, Wilcoxon]), за исключением функционирования в таких категориях, как d3351 - составление и изложение сообщения посредством знаков и символов ( $p=0,18$ [по критерию Уилкоксона, Wilcoxon]), d330 - речь и d3602 - использование техник общения (значения определителей идентичны до и после слухопротезирования).

Метод оценки факторов окружающей среды, влияющих на функционирование и ограничения жизнедеятельности пациентов в условиях слухового дефицита

Разработанный метод оценки факторов окружающей среды, влияющих на функционирование и ограничения жизнедеятельности пациентов в условиях слухового дефицита, с позиций МКФ включает перечень категорий (е1251 - вспомогательные средства и технологии коммуникации, е2501 - качество звука, е310 - семья и ближайшие родственники) и 
их параметров, описывающих факторы физической и социальной среды, а также критерии оценки степени выраженности барьеров, которые ограничивают или затрудняют активность и участие лиц с тугоухостью, и факторов облегчения, которые позволяют или улучшают выполнение задач и действий этой категорией граждан [6].

Проведено обследование 129 пациентов с применением разработанного нами метода оценки факторов окружающей среды, оказывающих позитивное или негативное влияние на их функционирование в условиях слухового дефицита.

Установлено, что наиболее понятным в сложной акустической ситуации является речевой материал, предъявляемый на фоне шума ветра. Результаты отличаются статистически значимо от каждого из остальных показателей (шум дождя, транспорта, многоголосия) с p<0,001. Наименее доступной для понимания становится речь с помехами в виде многоголосия. В этом случае уровни значимости различий составили с показателем «дождь» - $p=0,002$, а с показателем «транспорт» - $p=0,003$. Статистически значимой разницы между полученными данными разборчивости речи в условиях помех, которыми выступают дождь и транспорт, не обнаружено ( $p=0,593)$, что позволило сделать вывод об их идентичном маскирующим эффекте.

В ходе анализа полученных данных оценки эффективности акустической коррекции слуха обнаружена сильная корреляционная связь $\left(r_{s}=0,88, p<0,001\right)$ между результатами восприятия фразовой речи разговорной громкости в метрах и процентом правильно воспроизведенных многосложных слов, предъявляемых в тишине с интенсивностью 65 дБ УзД и на фоне шума (многоголосие) при отношении SNR = +6 дБ. Следовательно, существует возможность с высокой точностью предсказать, какими будут показатели разборчивости речи со слуховым протезом в различных акустических ситуациях по величине максимального расстояния, с которого услышанный речевой материал становится доступным для понимания. При восприятии предложений на расстоянии не более 3 метров в 100\% случаев (95\% ДИ от 93,5 до 100\%) разборчивость речи в тишине составляет не более $40 \%$, а на фоне шума - не более $20 \%$. При распознавании фраз с расстояния 3 метра и более в 100\% случаев (95\% ДИ от 76,6 до 93,3\%) доля правильно воспроизведенных многосложных слов в тишине составила не менее $45 \%$, а на фоне шума показатели имели большую вариабельность.

На основании проведенного анализа полученных результатов нами предложено заменить существующие в настоящее время в медико-социальной экспертизе критерии оценки социально неадекватного слуха восприятие речи разговорной громкости на расстоянии до 3 метров [11] - на показатели разборчивости речи в тишине не более $40 \%$ и на фоне шума - не более $20 \%$. Кроме того, применение новых критериев в количественной оценке "речевого слуха» как социальной категории будет способствовать объективизации измеряемых параметров, лежащих в основе выносимого экспертного решения, за счет использования аудиологического оборудования и исключит применение акуметрии, принципиально основанной на человеческом факторе. При этом к исследованию эффективности акустической коррекции слуха «живой речью» должны прибегать только как к ориентировочному методу. 


\section{Алгоритм экспертно-реабилитационной диагностики пациен- тов с последствиями заболеваний органа слуха}

Разработанные в ходе научного исследования современные методы, включающие параметры и критерии оценки последствий заболеваний органа слуха с позиций МКФ, лежат в основе экспертно-реабилитационной диагностики пациентов со слуховыми нарушениями. Точное описание в процессе ее проведения всех без исключения действий и решений с определенной последовательностью их исполнения визуализировано нами в виде упорядоченной блок-схемы, которая является основой алгоритма (см. рисунок).

Разработка алгоритма экспертно-реабилитационной диагностики пациентов с последствиями заболеваний органа слуха осуществлялась с учетом предъявляемых к его созданию требований. Он должен быть формально строгим, удобным в прочтении, легким для понимания, обладать высокой точностью [12]. Кроме того, в алгоритме отражен применяемый в Республике Беларусь принцип этапности осуществления экспертно-реабилитационной диагностики.

Учитывая тот факт, что в оценке функционирования индивида с позиций МКФ используется биопсихосоциальный подход, мы предложили при разработке алгоритма объединить перечень методов, предписывающих выполнение определенных действий и решений, в три основных блока: морфофункциональный, индивидуально-личностный и блок социальной интеграции.

Морфофункциональный блок включает:

- оториноларингологический осмотр с оценкой структур органа слуха;

- психологическую диагностику с оценкой функций памяти, внимания, регуляции эмоций;

- аудиологическое исследование с оценкой функций органа слуха.

При оториноларингологическом осмотре проводится риноскопия, эпи- и мезофарингоскопия, непрямая ларингоскопия, отоскопия, включая микроотоскопию. Для уточнения клинико-функционального диагноза назначается один из следующих методов исследования: рентгенография, компьютерная томография или магнитная резонансная томография. На основании детального описания выявленных патологических изменений в слуховом анализаторе по результатам проведенного оториноларингологического осмотра осуществляется определение степени их выраженности путем применения разработанного метода экспертной оценки нарушений структур органа слуха с позиций МКФ [6].

Психологическая диагностика включает методы оценки памяти (методика запоминания 10 слов) [8], внимания (таблицы Шульте) [8], эмоционально-волевой сферы (шкала ситуативной и личностной тревожности Спилбергера - Ханина) [8]. По результатам ее проведения определяется степень выраженности выявленных проблем с использованием критериев, описанных в инструкции по применению «Метод медицинской реабилитации пациентов с расстройствами шизофренического спектра с использованием оценки реабилитационного потенциала и реабилитационного прогноза» [8] и разработанных критериев оценки кратковременной памяти и функции регуляция эмоций с позиций МКФ [6]. 


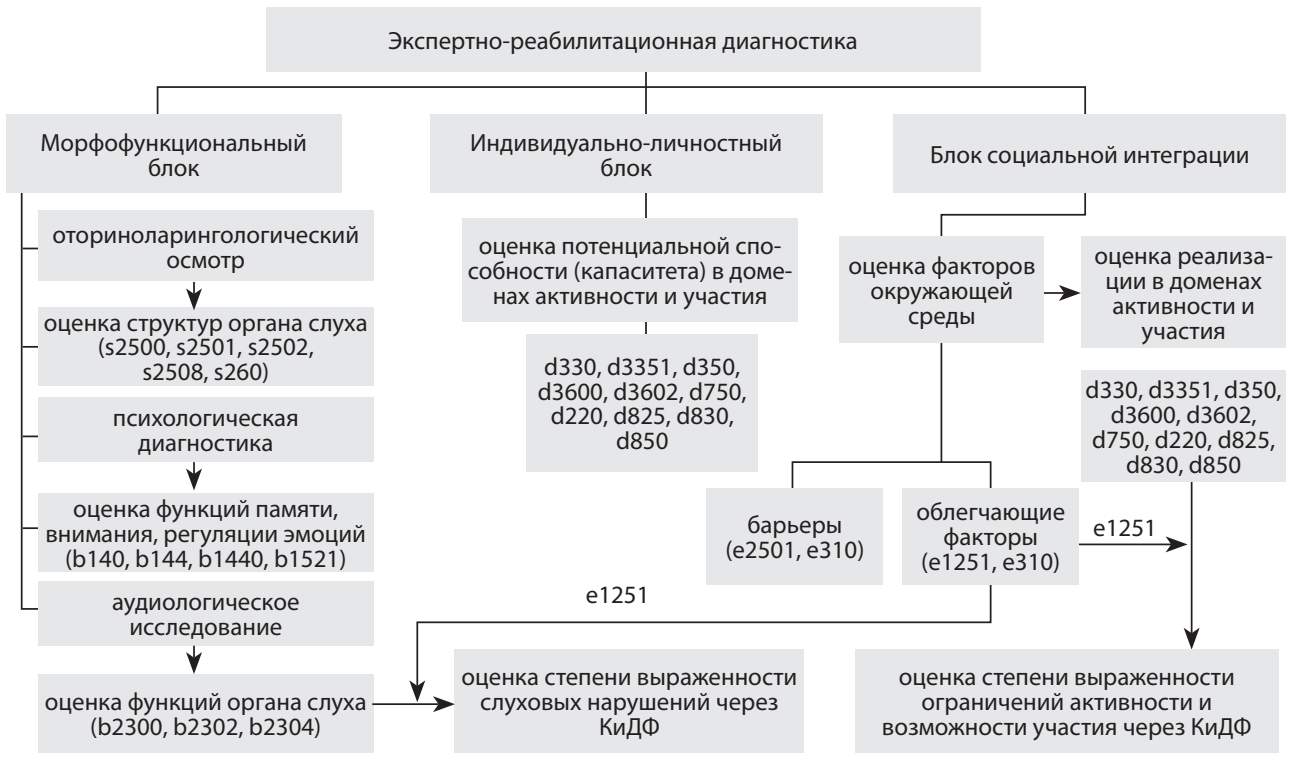

Клинико-функциональный экспертно-реабилитационный диагноз

\section{Алгоритм экспертно-реабилитационной диагностики пациентов с последствиями заболеваний органа слуха}

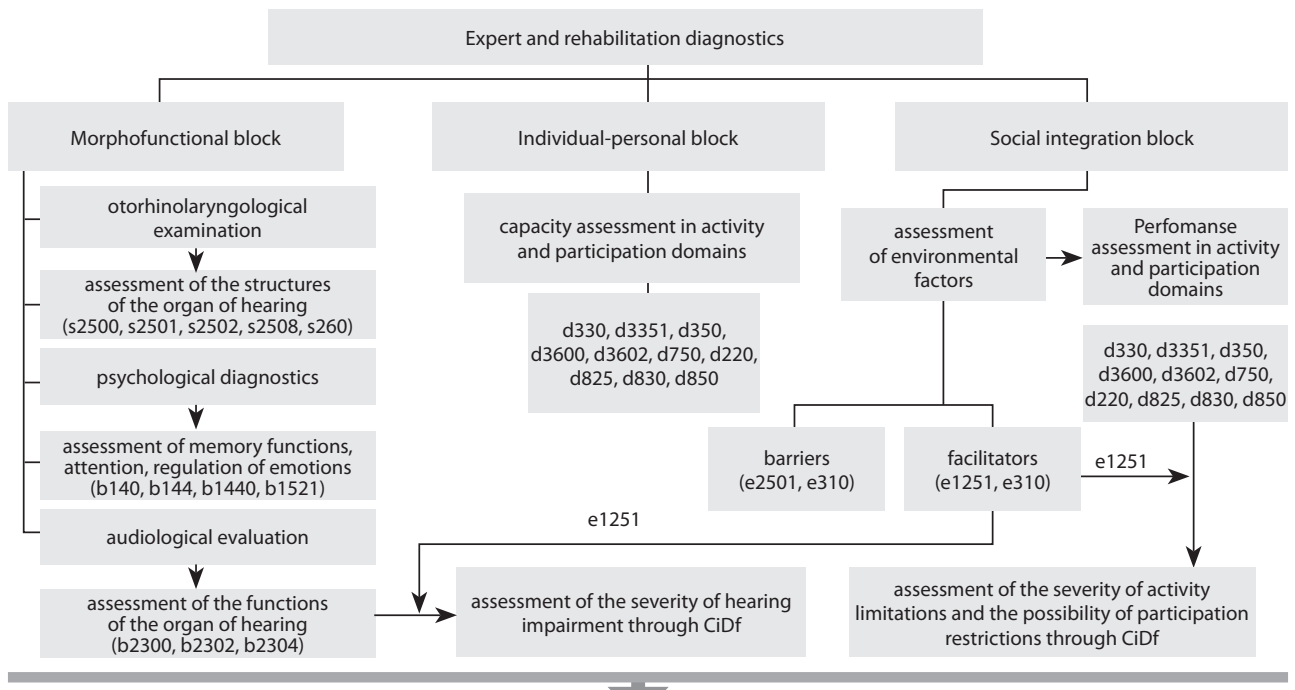

Clinical-functional expert-rehabilitation diagnosis 
Аудиологическое исследование проводится с использованием обязательных и дополнительных методов, перечень которых представлен выше. На основании полученных данных осуществляется определение степени выраженности выявленных проблем путем применения разработанного метода экспертной оценки нарушений функций органа слуха с позиций МКФ [6].

Индивидуально-личностный блок включает определение потенциальной способности (капаситета) в доменах сферы жизнедеятельности (задачи, действия) на основании разработанного метода оценки ограничений активности и возможности участия при последствиях заболевания органа слуха с позиций МКФ [6].

Блок социальной интеграции охватывает барьеры и облегчающие факторы с их количественной и качественной градацией по степени выраженности путем применения разработанного метода оценки факторов окружающей среды, влияющих на функционирование и ограничения жизнедеятельности пациентов в условиях слухового дефицита, с позиций МКФ [6]. Полученные данные используются для определения реализации в доменах активности и участия.

Оценка степени выраженности выявленных функциональных нарушений и ограничений жизнедеятельности в результате выполненных пошаговых действий осуществляется с учетом их компенсации слуховым протезом (код е-1251) через введенное нами понятие «категориальный индекс дефицита функционирования» (КиДФ). КиДФ - это обобщенный показатель оценки ограничений жизнедеятельности человека (нарушений, ограничений активности и возможности участия), который включает различные домены, категории доменов и характеризует степень выраженности выявленных проблем с учетом их компенсации облегчающими факторами окружающей среды.

Конечной целью экспертно-реабилитационной диагностики пациентов с последствиями заболеваний органа слуха является вынесение клинико-функционального экспертно-реабилитационного диагноза в соответствии с МКБ-10 и МКФ. При этом указывается результат оценки степени выраженности слуховых нарушений и ограничений активности и возможности участия через КиДФ.

\section{- ВЫВОДЫ}

1. Разработана методика экспертно-реабилитационной диагностики пациентов с последствиями заболеваний органа слуха, основанная на концепции МКФ и включающая новые методы оценки нарушений структур и функций органа слуха, ограничений жизнедеятельности, обеспечивающая объективность выносимого экспертного решения.

2. При направлении пациентов на медико-социальную экспертизу аудиологическое исследование должно включать не только обязательные, но и дополнительные методы. Это позволит уточнить топику поражения слухового анализатора и объективизировать степень выраженности слуховых нарушений, в том числе у лиц с различными формами установочного поведения или особенностями психофизического развития.

3. Разработанный перечень параметров категорий доменов функций и структур организма у пациентов с последствиями заболеваний 
органа слуха и критерии их оценки с позиций МКФ позволяют получить структурированное и всестороннее описание степени выраженности нарушений показателей здоровья и функциональных возможностей этой категории лиц, а также выбрать способ акустической коррекции слуха.

4. Способность локализовать источник звука в горизонтальной плоскости зависит от асимметрии слуха по порогам ( $\left.r_{s}=0,98, p<0,001\right)$. При асимметрии слуха более 40 дБ возникают трудности в локализации источника звука в тишине и становится невозможным определить направление прихода звуковой волны на фоне помехи в горизонтальной плоскости, что важно учитывать при оценке степени выраженности ограничения жизнедеятельности в категории «способность к ориентации».

5. Для исключения неправильного выбора и неадекватной настройки слухового аппарата, а также аггравации полученных показателей оценки эффективности слухопротезирования необходимо использовать упрощенный вариант традиционной речевой аудиометрии с моноуральным предъявлением односложных слов через головные телефоны в тишине на лучше слышащее ухо при комфортном уровне громкости, по данным которой можно спрогнозировать результаты речевой аудиометрии со слуховым аппаратом в свободном звуковом поле в аналогичной акустической ситуации при входном сигнале, представленном многосложными словами интенсивностью 65 дБ УЗД. Установлено, что между вышеуказанными показателями существует прямая регрессионная зависимость (коэффициент детерминации $\left.\mathrm{R}^{2}=0,56, \mathrm{p}<0,05\right)$.

6. У всех лиц со слуховым дефицитом выявлены различной степени выраженности нарушения памяти, внимания и эмоционально-волевой сферы, которые требуют дальнейшего обследования у врача специалиста в области оказания психиатрической помощи (с учетом установленной степени тяжести когнитивных расстройств) или специалиста в области оказания психологической помощи.

7. Разработанный метод оценки ограничений активности и возможности участия у пациентов с последствиями заболеваний органа слуха позволяет расширить перечень измеряемых параметров, определить уровень функционирования лиц в условиях слухового дефицита, четко идентифицировать возникающие вследствие этого проблемы и обеспечить объективизацию выносимого экспертного решения.

8. Обнаружена сильная обратная корреляционная связь между уровнем речевого развития и возрастом наступления тугоухости $\left(r_{s}=0,70\right.$, $\mathrm{p}<0,001)$. Поэтому нарушение речи у взрослых лиц с тугоухостью является стойким дефектом, который не компенсируется акустическим средством коррекции слуха. Оценка его степени выраженности имеет важное значение при установлении инвалидности.

9. Разработанный метод оценки факторов окружающей среды, влияющих на функционирование и ограничения жизнедеятельности пациентов в условиях слухового дефицита, позволяет определить не только степень выраженности возникающих барьеров при вовлечении этой категории лиц в жизненные ситуации, но и «социальную 
достаточность слуха» и пути ее достижения с использованием различных способов коррекции слухового дефекта.

10. Установлено, что наибольшими препятствиями для понимания речевого материала являются помехи в виде многоголосия. В меньшей степени на восприятие речи влияет шум дождя и транспорта. Наиболее понятным в сложной акустической ситуации является речевой материал, предъявляемый на фоне ветра. Полученные результаты можно использовать при формировании рекомендаций для трудоустройства лиц с нарушениями слуха.

11. Обнаружена сильная корреляционная связь $\left(r_{s}=0,88, p<0,001\right)$ между восприятием фразовой речи разговорной громкости в метрах и процентом правильно воспроизведенных многосложных слов, предъявляемых в тишине с интенсивностью 65 дБ УЗД и на фоне шума (многоголосие) при отношении SNR $=+6$ дБ. При восприятии предложений на расстоянии не более 3 метров в 100\% случаев (95\% ДИ от 93,5 до 100\%) разборчивость речи в тишине составляет не более $40 \%$, а на фоне шума - не более $20 \%$. При распознавании фраз с расстояния 3 метра и более в 100\% случаев (95\% ДИ от 76,6 до 93,3\%) доля правильно воспроизведенных многосложных слов в тишине составила не менее 45\%, а на фоне шума показатели имели большую вариабельность. На основании полученных данных выведено понятие «социально неадекватного слуха», включающее разборчивость речи в тишине не более $40 \%$, а на фоне шума - не более $20 \%$. Его применение в количественной оценке «речевого слуха» как социальной категории обеспечит объективизацию измеряемых параметров, лежащих в основе экспертного решения, за счет исключения метода акуметрии, содержащего субъективную составляющую.

12. Установлено, что применение современных акустических средств коррекции слуха позволяет обеспечить высокую эффективность слухопротезирования, в том числе при III и IV степенях тугоухости.

13. Разработанный алгоритм экспертно-реабилитационной диагностики пациентов со слуховыми нарушениями, основанный на современных методах и критериях оценки последствий заболеваний органа слуха с позиций МКФ, обеспечит многосторонний и комплексный подход к оценке биологических, психологических и социальных аспектов функционирования индивида со слуховым дефицитом на различных уровнях (морфофункциональном, индивидуально-личностном и уровне социальной интеграции). Его применение в медико-социальной экспертизе будет способствовать высокой степени объективности и индивидуализации выносимого экспертного решения.

Вклад авторов: Смычек В.Б. - концепция и дизайн исследования, редактирование, руководство реализацией; Макарина-Кибак Л.Э. - концепция и дизайн исследования, редактирование, руководство реализацией; Козлова С.В. - концепция и дизайн исследования, проведение инструментального обследования, сбор клинического материала, обработка данных, написание текста, оформление статьи; Мириленко А.П. дизайн исследования, статистическая обработка. 
Authors' contribution: Smychek V. - concept and design of the study, editing, management of implementation; Makaryna-Kibak L. - concept and design of the study, editing, management of implementation; Kozlowa S. concept and design of the study, instrumental examination, collection of clinical material, data processing, text writing, article design; Mirilenko A. design of the study, statistical processing.

Конфликт интересов. Авторы заявляют об отсутствии конфликта интересов.

Conflict of interest. The authors declare no conflicts of interest.

\section{- ЛИТЕРАТУPA/REFERENCES}

1. Смычек В., Козлова С. (2020). Konceptual'noe obosnovanie podhodov k modernizacii sushchestvuyushchej sistemy mediko-social'noj ekspertizy pacientov s posledstviyami zabolevanij organa sluha [Conceptual substantiation of approaches to the modernization of the existing system of medical and social examination of patients with the consequences of diseases of the organ of hearing]. Problems of public health organization and informatization, no 2 (103), pp. 41-51.

2. WHO (2001) Mezhdunarodnaya klassifikaciya funkcionirovaniya, ogranichenij zhiznedeyatel'nosti $i$ zdorov'ya [International Classification of Functioning, Disability and Health], Geneva: WHO, 342 p. (in Russian)

3. Boboshko M. (2012) Rechevaya audiometriya [Speech audiometry]. St. Petersburg: PFSPSMU, 64 p. (in Russian)

4. (2019) Metod opredeleniya ustanovochnogo povedeniya u pacientov so sluhovymi, zritel'nymi, statodinamicheskimi, psihicheskimi narusheniyami, bolevym sindromom: instrukciya po primeneniyu № 228-1218 [Method for determining attitudinal behavior in patients with auditory, visual, statodynamic, mental disorders, pain syndrome: instructions for use № 228-1218]. Minsk: RSPC of Medical Assessment and Rehabilitation, 42 p. (in Russian)

5. Smychek V. (ed.) (2019) Simulyaciya i aggravaciya v ekspertnoj praktike [Simulation and aggravation in expert practice]. Minsk: Kolorgrad, $342 \mathrm{p}$.

6. (2019) Metod kompleksnoj ocenki i vosstanovleniya deficita funkcionirovaniya pacientov s posledstviyami zabolevanij organa sluha s pozicij Mezhdunarodnoj klassifikacii funkcionirovaniya, ogranichenij zhiznedeyatel'nosti i zdorov'ya: instrukciya po primeneniyu № 209-1218 [The method of comprehensive assessment and restoration of the deficit in the functioning of patients with the consequences of diseases of the hearing organ from the standpoint of the International classification of functioning, disabilities and health: instructions for use № 209-1218]. Minsk: RSPC of Medical Assessment and Rehabilitation, RSPC of Otorhinolaryngology, 30 p. (in Russian)

7. (2018) Metod medicinskoj reabilitacii pacientov s rasstrojstvami shizofrenicheskogo spektra s ispol'zovaniem ocenki reabilitacionnogo potenciala $i$ reabilitacionnogo prognoza: instrukciya po primeneniyu № 141-1217 [Method of medical rehabilitation of patients with schizophrenic spectrum disorders using assessment of rehabilitation potential and rehabilitation prognosis: instructions for use № 141-1217]. Minsk: RSPC of Medical Assessment and Rehabilitation, RSPC for Mental health, 27 p. (in Russian)

8. Belova A. (ed.) (2002) Simulyaciya i aggravaciya v ekspertnoj praktike [Simulation and aggravation in expert practice]. Moskva: Antidor, 98 p. (in Russian)

9. Leongard E., Samsonova E. (1997) Razvitie rechi detej snarushennym sluhom v sem'e [Development of speech in children with hearing impairments in the family]. Moscow, 222 p. (in Russian)

10. Vojtenko R., Sakovskaya V., Filippova M. (2018) Rasstrojstva kognitivnoj sfery [Cognitive disorders]. SPb: SPbIUVEK, 54 p. (in Russian)

11. (2000) Metodicheskie podhody $k$ ocenke ogranichenij zhiznedeyatel'nosti $i$ sostavleniyu programm mediko-social'noj reabilitacii bol'nyh $s$ posledstviyami zabolevanij organa sluha: metodicheskie rekomendacii № 10-0001 [Methodological approaches to assessing the disabilities and drawing up programs of medical and social rehabilitation of patients with the consequences of diseases of the organ of hearing: methodological recommendations № 10-0001]. Minsk, 42 p. (in Russian)

12. Parondzhanov V. (2017) Pochemu vrachi ubivayut $i$ kalechat pacientov, ili Zachem vrachu blok-skhemy algoritmov? [Why do doctors kill and maim patients, or why does a doctor need flowcharts?]. Moskva: DMK-Press, 340 p. (in Russian)

Подана/Submitted: 08.08.2021

Принята/Accepted: 23.08.2021

Контакты/Contacts: kozlowasweta@tut.by 